\title{
The burden of disease and the cost of illness attributable to child maltreatment in Japan: long-term health consequences largely matter
}

Xiuting Mo ${ }^{1,2}$, Ruoyan Tobe Gai ${ }^{1,3^{*}}$, Yoshiyuki Tachibana ${ }^{4}$, Timothy Bolt ${ }^{5}$, Yoshimitsu Takahashi ${ }^{2}$ and Takeo Nakayama ${ }^{2}$

\begin{abstract}
Background: Child maltreatment leads to enormous adverse short- and long-term health outcomes. The aim of this study is to estimate the burden of disease and the cost of illness attributable to child maltreatment in Japan.

Methods: An incidence-based top-down cost of illness analysis was conducted to estimate medical costs and burden of disease attributable to child maltreatment based on a societal perspective. The assessment included short-term and long-term medical costs and burden of disease measured by Disability-Adjusted Life Years (DALYs) that generates mortality and morbidities, based on several national surveys and systematic review. We considered the main types of child maltreatment as exposure, for which the incidence was obtained from literature review. Based on population attributable fractions (PAFs), burden of disease of physical and mental health consequences attributable to child maltreatment were estimated. Then DALYs were converted into monetary value. The lifetime economic burden was finally estimated by combining with medical costs and subject to sensitivity analysis.
\end{abstract}

Results: The lifetime disease burden expressed in DALYs was estimated at 1,047,580 DALYS (95\% CI 788,388 - 1326, 80 DALYs) for the cohort victims in 2016. Based on the incidence according to literature review, the overall lifetime economic burden was 50.24 billion USD, equivalent to 1.3 million times of gross domestic product (GDP) per capita. Among the total economic burden, costs of suffering and pain based on DALYs were accounting for $81.3 \%$. These estimates were 7-8 times of conservative estimates which used incidence data from official reported cases.

Conclusions: This study found that the national lifetime cost was huge and equivalent to 1.3 million GDP per capita, and its burden of disease was approximately equal to that of colon and rectum cancers or stomach cancer. Our findings particularly in terms of revealed the considerable burden of disease in long term and potential effects of the strengthened maternal and child care as the preventive strategy.

Keywords: Child maltreatment, Burden of disease study, Lifelong health consequences, Disability-adjusted life year (DALY), Cost-of-illness

\footnotetext{
* Correspondence: gai-ruoyan@ipss.go.jp

1 Department of Health Policy, National Center for Child Health and Development, Tokyo, Japan

${ }^{3}$ Department of Empirical Social Security Research, National Institute of

Population and Social Security Research, Uchisaiwaicho 2-2-3, Chiyoda-ku,

Tokyo 1000011, Japan

Full list of author information is available at the end of the article
}

(c) The Author(s). 2020 Open Access This article is licensed under a Creative Commons Attribution 4.0 International License, which permits use, sharing, adaptation, distribution and reproduction in any medium or format, as long as you give appropriate credit to the original author(s) and the source, provide a link to the Creative Commons licence, and indicate if changes were made. The images or other third party material in this article are included in the article's Creative Commons licence, unless indicated otherwise in a credit line to the material. If material is not included in the article's Creative Commons licence and your intended use is not permitted by statutory regulation or exceeds the permitted use, you will need to obtain permission directly from the copyright holder. To view a copy of this licence, visit http://creativecommons.org/licenses/by/4.0/ The Creative Commons Public Domain Dedication waiver (http://creativecommons.org/publicdomain/zero/1.0/) applies to the data made available in this article, unless otherwise stated in a credit line to the data. 


\section{Background}

Child maltreatment is a raising concern in public health and social welfare in Japan [1] The reported number of suspected cases of child maltreatment is increasing, from 37,323 in 2006 to 122,575 in 2016 [2]. According to the Ministry of Health, Labour and Welfare (MHLW) of Japan, child maltreatment is categorised into four essential types, physical, sexual or psychological (including witnessing domestic violence, WDV) abuse and neglect [3]. Exposure to multiple types and repeated episodes of maltreatment during childhood is associated with high risks to enormous adverse health outcomes, causing a significant social and economic burden on individuals, families, and societies. Those adverse outcomes during childhood include child death, injuries and disabilities, developmental and behavioural problems. Moreover, the related physical and mental health conditions persist into adulthood, leading to the onset of chronic diseases, depression, drug, alcohol misuse and risk sexual behaviour, suicide ideation $[4,5]$.

The government has introduced a couple of protective measures, with increasing public budget [6-8]. Assessment of costs and burden of disease helps development of resource allocation and priority setting in public sector. Paralleling with growing concerns on child maltreatment, the number of the related analysis of the prevalence, health consequences and economic burden is increasing. So far, for the economic burden there are two typical research frameworks: one is a comprehensively costs evaluation from healthcare, social, educational areas, and loss in productivity et al. [9-13]; another one is to measure related economic and disease burden [14, 15]. Wada et al. (2014) reported the social costs of child abuse in Japan included direct costs of dealing with abuse and the indirect costs related to longterm damage from abuse during the fiscal year 2012. On the other hand, the first framework is likely to underestimate long-term deleterious effects of child maltreatment, on which evidence derived from longitudinal studies is less available compared to that on the short-term counterpart [16]. By integrating previous evidence, our costof-illness study aimed to assess lifetime economic and disease burden of mortality and morbidities attributed to child maltreatment based on the later framework, in order to address the evidence gap. We extended cost calculations for monetary values converted from Disability Adjusted Life Years (DALYs), covering related mortality and morbidities [17].

\section{Methods}

An incidence-based (victims estimated by incidence), top-down approach (or attributable risk approach, measuring the proportion of a disease that is due to exposure to risk factor) was applied in this study from a societal perspective [18]. We employed the following steps to estimate the total economic burden, constituted by direct and indirect costs:

1. Population attributable fraction (PAF) was generated to estimate long-term impacts/costs attributed to child maltreatment.

2. Short-term and long-term direct medical costs were assessed by using national expenditure databases.

3. Indirect costs measured include productivity loss caused by abusive head trauma and economic burden deriving from DALYs.

4. Finally, sensitivity analyses were performed for the plausible range of the discount rate and the incidence / prevalence.

\section{Estimating PAF}

In the top-down approach, PAF for each disease $i$ measured that how health outcomes and their associated costs may be attributed to child abuse, using the following formula $[19,20]$ :

$$
P A F i=\frac{P\left(R R_{i}-1\right)}{P\left(R R_{i}-1\right)+1}
$$

( $P$ : prevalence of child abuse; $R R$ : the relative risk of the outcome $i$ in those who experienced child abuse compared with those who did not)

\section{Risk ratio (RR) or odds ratio (OR)}

Several previous related systematic reviews and metaanalyses summarised the relevant health consequences $[5,15,21,22]$. As adverse childhood experiences (ACEs) often intertwine with child maltreatment, cluster in children's lives and cumulatively lead to poor health outcomes, we pooled the ORs from a recent systematic review and meta-analysis for the effect of multiple ACEs on health [5], rather than that for each category of child maltreatment.

\section{The pooled prevalence}

A literature review was performed to synthesize the evidence on epidemiological characteristics the consequences in Japan. The review focused on those published between December 2010 and March 2018 on Medline (PubMed), Web of Science, SCOPUS and CiNii Articles (Japanese literature). Details of the search strategy, search terms used, and inclusion and exclusion criteria are provided in the Additional file 2. We combined our review results with those studies in Japan included in an existing systematic review [23], and calculated the simple size-weighted mean incidence/prevalence. In addition, the median value was also calculated to 
examine the robustness (Supplementary Table 1). The annual incidence rate was obtained by the formula: [24].

$$
\text { Incidence rate }=\frac{\text { Prevalence }}{\text { Average duration }}
$$

Due to the lack of local data on the average duration, we adopted that published in Australia [12]: the average 5.6 years for physical abuse and 2.9 years for sexual abuse. Based on this finding, the weighted average of 4.6 years was used for other categories of abuse.

\section{Direct medical costs}

\section{Short-term medical costs}

For abusive head trauma (AHT) is the leading cause of death due to child abuse among children younger than 5 years old, [25] we estimated its hospitalization costs as short-term medical costs by multiplying the incidence of AHT under 3 years old [26], the agespecific population in 2016 [27], and admission medical fee per case [26].

There were two reported incidences: one is the "possible" incidence considering countable possibility of AHT cases at most and another one is the "presumptive" incidence representing victims had intracranial injuries or intentional injuries with certain ICD-10 code. We used the "possible" incidence for the general calculation and the latter one in sensitivity analysis. The total possible AHT cases aged under 3 years was about 8 times of the presumptive counterparts [26].

\section{Long-term medical costs}

For long-term medical costs, we used National healthcare expenditures 2016 and Patient Survey 2014 to simulate disease burden of relevant health consequences by sex and age group $(0-14,14-44,45-64$, above 65), and then multiplied with PAFs to calculate the attributable costs in the victim cohort of 2016 [5, $26,28]$. On the other hand, we did not include selfharm and collective violence because of the limitation to distinguish the two in the reported overall injury cases.

\section{Indirect costs}

In this study, we considered differential and loss of earning as a result of human capital depreciation is caused by mortality and morbidities. It was presented as a monetary value of DALYs and GDP per capita $[15,29]$.

\section{DALYs and its monetary value}

The disease burden indicator DALY aggregates years of life lost for premature death and years lost due to disability for morbidities [19]. Related data were obtained from the WHO Global Burden of Disease (GBD) [30]. Using the pooled ORs as described by Karen et al. (2017) [5], we matched each related health outcome [5] with the cause of disease burden in the WHO GBD categories, though it was difficult to match some outcomes with the cause of GBD (Supplementary Table 2).

Then, monetary value was converted from DALY attributable to child maltreatment by multiplying DALY and GDP per capita [17] with adjustment of purchasing power parity in 2016 [31].

\section{Productivity losses due to AHT fatal cases}

Productivity loss due to fatal cases of child maltreatment was calculated based on the reported fatal cases, which figure was obtained from official data [32], and the average lifetime income subject to discounting. In 2016, there were 67 abuse-related deaths reported in Japan (not including family suicide), with the average onset age of 2 years [32]. The discounted lifetime income (from 18 to 65 years old) was calculated by assuming the long-term growth in labour productivity to be $1 \%$ per year [10].

\section{DALYs losses of survival AHT}

For disease burden due to survival AHT, we considered sequelae such as vision loss, brain damage, and reduced life span [33], and long-term health consequences as developing diseases in adulthood. We calculated the disease burden of AHT in 2016 by multiplying average cases and the estimated mean lifetime DALY loss per case at different severity (mild, moderate and severe) [33].

\section{Long-term DALYs losses of other diseases}

Then the long-term health consequences were calculated using the following formula:

$$
\begin{aligned}
& \text { DALY losses }=\Sigma\left(\mathrm{PAF}_{\mathrm{i}} * \text { original } \mathrm{DALY}_{\mathrm{i}}\right) \\
& (\mathrm{i}: \text { different child abuse }- \text { related health outcome })
\end{aligned}
$$

\section{Sensitivity analyses}

A discount rate of $2 \%$ is generally performed which was recommended in the domestic guideline for costeffectiveness analysis [34]. Whereas especially in the US, a discount rate of $3 \%$ has been selected and applied in the cost estimate reports of Centers for Disease Control and a best practices for the Social Return on Investment analysis recommended by experts and guidelines [9]. As such the parameter potentially affects the finally results, we adopted a plausible range of 0,2 to $3 \%$ for sensitivity analysis. 
In addition, we also calculated costs and disease burden using the incidence/prevalence data based on officially reported child abuse cases. To calculate the conservative incidence of child abuse by categories, we obtained the official data of victim cases reported by child consultation facilities in 2016 [2] and then divided them by the total population number in corresponding age [27]. Data by sex were not available. Co-current information was not available and the overlapped cases were not considered (Supplementary Table 3). The initial victim age is assumed to be 7 years old, according to an age-weighted incidence calculation based on official reported cases [2]. We assumed the probable abuse-related death cases to be 8 times of the reported cases based on the ratio of the presumptive and the possible incidence of AHT cases among children aged under 3 years [26].

\section{Results}

The main results showed in tables were discounted at $2 \%$ and conservative estimates were given for sensitivity analyses.

\section{The pooled incidence / prevalence and disease burden}

The estimations on different types of child maltreatment incidence draw from literature reviews varied. Regarding differences between sex, except physical abuse, girls suffered more than boys in sexual abuse and witnessing domestic violence (Table 1). The estimated lifetime disease burden associated with child maltreatment onset in 2016 was considerable, 1,047, 580 DALYs with a $95 \%$ CI of 788,388 DALYs to 1326,806 DALYs (Table 2). The top causes of total disease burden due to child abuse were suicide attempts (34\%), cancer (22\%), cardiovascular disease (13\%) and depression (9\%).

\section{Cost-of-illness analysis for child maltreatment}

Table 3 demonstrates lifetime costs attributed to child abuse onset in 2016. The total direct cost was estimated

Table 1 Estimated incidence/prevalence of child abuse in Japan

\begin{tabular}{|c|c|c|c|c|}
\hline \multirow[t]{2}{*}{ Estimates $^{a}$} & \multicolumn{2}{|c|}{ Prevalence } & \multicolumn{2}{|c|}{ Incidence $^{\mathrm{b}}$} \\
\hline & Male & Female & Male & Female \\
\hline Physical abuse (\%) & 8.40 & 6.69 & 1.50 & 1.19 \\
\hline Sexual abuse (\%) & 0.33 & 7.38 & 0.11 & 2.54 \\
\hline \multicolumn{5}{|l|}{ Psychological abuse } \\
\hline WDV c (\%) & 9.94 & 16.75 & 2.16 & 3.64 \\
\hline Other ${ }^{d}(\%)$ & 5.64 & 5.95 & 1.23 & 1.29 \\
\hline Neglect (\%) & 8.89 & 9.01 & 1.93 & 1.96 \\
\hline
\end{tabular}

${ }^{a}$ sample sized weighted mean value

${ }^{\mathrm{b}}$ Incidence rate $=$ Prevalence $/$ Average duration

c WDV: witnessing domestic violence

${ }^{d}$ not specified as WDV, often expressed as emotional/psychological abuse to be USD 8930.6 million (95\%CI: 6502.1 million-11, 674.4 million) while the total indirect cost was estimated to be USD 41,305.7 million (95\%CI: 30,965.5 million-52, 429.2 million), accounting for $82.2 \%$ of the total lifetime costs, which were almost 1.3 million times GDP per capita. Economic loss initiated from DALYs in longterm (costs of suffering and pain) accounted for $81.3 \%$ of the overall estimates.

\section{Sensitivity analyses}

Conservative estimates based on the reported cases incidence showed a tendency similar to that observed in the disease burden based on the literature review, among which psychological abuse (including WDV) accounted for the majority of reported child abuse cases (51.5\%). However, the incidence estimated from the review were much higher than those reported by child protection agencies (the conservative estimation), leading to about 7-8 times difference gap on child maltreat burden by difference discount rate $(0,2,3 \%)$. (Table 4$)$.

\section{Discussion}

Our results indicated that disease and economic burden attributable to child maltreatment is substantial. In particular, that originated from the long-term health consequences accounts for the majority.

Based on literature review, the pooled incidence of child maltreatment in Japan is much higher than officially reported, which is consistent with the findings of other studies [10, 12, 35]. Because of difficulty to identify the actual cases and a public attitude to consider child abuse as a private affair in the society, the officially reported cases are likely to represent the tip of an iceberg.

Psychological abuse (including WDV) represented the majority of reported cases. The results of the literature review also showed a gender difference in the prevalence of the four types of child abuse (size weighted mean values), girls were found to be more likely to experience the harmful practices compared to boys, particularly sexual abuse. This tendency was also observed in other countries in East Asia and Pacific region [15]. Comparing those living in other countries in the East Asia and Pacific region [15, 23], Japanese children tended to less likely to experience physical abuse (boys: $8.40 \%$ vs. $16.76 \%$; girls: $6.69 \%$ vs. $15.42 \%)$.

Although it is difficult to directly compare the results across different study settings due to the different methodologies, parameters and target populations adopted, the ingredients of the lifetime economic and disease burden considered in our study, including medical costs and monetary value of disease burden, are similar to that adopted in previous studies [10, 
Table 2 long-term DALY lost attributable to child abuse in Japan

\begin{tabular}{llll}
\hline${\text { Diseases attributed to child abuse }{ }^{\text {a }}}$ & DALYs & $95 \%$ Confidence interval & 399,629 \\
\hline Suicide attempt & 356,773 & 300,916 & 324,600 \\
Cancer & 229,020 & 149,110 & 194,281 \\
Cardiovascular disease & 136,215 & 86,896 & 116,032 \\
Depression & 96,998 & 79,403 & 102,188 \\
Respiratory disease & 79,628 & 59,650 & 58,506 \\
Liver or digestive disease & 45,286 & 33,453 & 45,572 \\
Anxiety & 32,436 & 21,159 & 30,003 \\
Problematic drug use & 25,410 & 20,857 & 18,549 \\
Abusive head trauma & 18,504 & 18,504 & 12,059 \\
Problematic alcohol use & 10,002 & 8082 & 12,512 \\
Diabetes & 8072 & 4314 & 7728 \\
Sexually transmitted infections & 5023 & 2717 & 4721 \\
Violence victimisation & 3865 & 3054 & 427 \\
Violence perpetration & 348 & 272 & 1326,806 \\
Total & $1,047,580$ & 788,388 & 51.72 \\
DALYs monetary value (billion, US\$) & 40.84 & 30.73 & \\
\hline
\end{tabular}

${ }^{a}$ simple size weighted mean prevalence at $2 \%$ discounted rate

12]. Still our results showed that the disease burden was about 7-8 times of the conservative estimation due to the huge gap of incidence generated from literature and that officially reported. The number is consistent with an Australian research that showed a wide distribution of the annual prevalence, ranging from 0.85 to $4.6 \%$ [12]. In the conservative lifetime course simulation, the initial victim age is assumed to be 7 years old according to an age-weighted incidence calculation based on official reported cases, which was also consistent with previous studies [9].

Our study in particular highlighted DALYs in longterm attributable to child maltreatment, accounting for a relevant proportion (81.3\%) in the overall lifetime costs. The estimation of disease burden attributed to child maltreatment (1,047,580 DALYs) was comparable to the total DALYs due to colon and rectum cancers $(1,043,335$ DALYs in 2015), or stomach cancer $(1,002,252$ DALYs in 2015) [30].

To our knowledge, this is the first study to estimate lifetime economic burden of child maltreatment in Japan based on an epidemiological model. The idea of this method is to convert disease-induced losses of well-being into economic terms by multiplying the annual number of lost life years due to disease by sub-reginal per capita income. So far, few studies had ever taken this part of costs into account, potentially leading to an underestimation of health and economic

Table 3 Lifetime costs attributable to child abuse for the first time in 2016

\begin{tabular}{|c|c|c|c|c|}
\hline Items of the costs (USD, million) & & $95 \% \mathrm{Cl}$ & & $\%$ \\
\hline Direct costs (Medical costs) & 8930.6 & 6502.1 & $11,674.4$ & $17.8 \%$ \\
\hline Short-term (AHT) & 4.9 & 3.8 & 6.0 & $0.0 \%$ \\
\hline Long-term (other diseases) & 8925.7 & 6498.3 & $11,668.5$ & $17.8 \%$ \\
\hline Indirect costs & $41,305.7$ & $30,965.5$ & $52,429.2$ & $82.2 \%$ \\
\hline Abuse death ${ }^{a}$ (Productivity losses) & 468.2 & 234.1 & 702.3 & $0.9 \%$ \\
\hline Survival AHT (DALYs) ${ }^{b}$ & 721.0 & 719.0 & 727.0 & $1.4 \%$ \\
\hline Long-term loss of other diseases ${ }^{b}$ & $40,116.4$ & $30,012.4$ & $50,999.8$ & $79.9 \%$ \\
\hline Total costs & $50,236.3$ & $37,467.7$ & $64,103.6$ & 1.3 million GDP per capita \\
\hline
\end{tabular}

AHT Abusive head trauma

a: we used 0.5-1.5 times of base line data for range costs of child abuse

${ }^{b}$ : Costs of suffering and pain: DALYs converted into monetary value by multiplying a gross domestic product per capita 
Table 4 Sensitivity analyses on incidence resource and discounted rate

\begin{tabular}{|c|c|c|c|c|c|c|}
\hline \multirow{2}{*}{\multicolumn{2}{|c|}{$\begin{array}{l}\text { Sensitivity Analysis } \quad \text { Disease bu } \\
\text { Literature based estimation }^{\text {a }}\end{array}$}} & \multicolumn{2}{|l|}{ ALYS $(95 \% \mathrm{Cl})$} & \multicolumn{3}{|c|}{ Economic burden (USD, million) (95\%Cl) } \\
\hline & & & & & & \\
\hline$d r=3 \%$ & 687,769 & 524,469 & 861,008 & $33,194.78$ & $25,024.37$ & $41,959.60$ \\
\hline$d r=2 \%$ & $1,047,580$ & 788,388 & 1326,806 & $50,236.3$ & $37,467.7$ & $64,103.6$ \\
\hline $\mathrm{dr}=0 \%$ & $2,784,035$ & $2,041,484$ & $3,605,376$ & $132,634.80$ & $96,800.53$ & $172,400.50$ \\
\hline \multicolumn{7}{|c|}{ Conservative estimation $^{b}$} \\
\hline $\mathrm{dr}=3 \%$ & 99,131 & 64,477 & 146,048 & 4434.64 & 2897.38 & 6495.84 \\
\hline $\mathrm{dr}=2 \%$ & 143,520 & 93,294 & 211,257 & 6426.83 & 4197.12 & 9408.04 \\
\hline$d r=0 \%$ & 341,670 & 222,038 & 501,550 & $15,425.35$ & $10,071.83$ & $22,528.25$ \\
\hline
\end{tabular}

$d r$ discounted rate

${ }^{\text {a }}$ Estimated based on literature review, simple size weighted average prevalence

${ }^{b}$ Estimated based on the number of consultation cases disposed about child abuse at child guidance centres. Probable estimate of abuse death was assumed about 8 times (confirmed AHT cases/possible cases $=8$ ) of the costs of conservative estimate

impacts of child maltreatment. In addition, we adopted conservative calculation methodology in the sensitivity analyses to estimate the burden of child maltreatment for more reliable range estimations.

There are several limitations to this study. First, the co-occurrence of multiple types of child abuse is prevalent [35], resulting in difficulties to identify the adverse effects separately. In order to minimize possible consequent overestimation, we used the pooled ORs of multiple adverse childhood health experiences instead of each types of child maltreatment and its severity. Second, we focused on the economic burden due to the mortality and morbidity of child maltreatment but did not consider non-health human capital aspects, to address the knowledge gap. Third, like other economic burden estimation studies, the availability of data on the related medical costs were limited. We nevertheless targeted major health consequences and explored their unit costs for the estimates [26].

Recently in Japan, a continuum of intensive supports to mothers and child-rearing families encompassing the reproductive cycle has been widely implemented in most local authorities. Such an integral approach serves as an essential preventive strategy against child maltreatment and other harmful practices by early detection and intervention of highrisk households in pregnancy, postpartum and childrearing periods. This study can provide decision makers information on the economic burden of child maltreatment, as well as an important input in future economic evaluations (cost-effectiveness analysis) on currently ongoing intervention and policy. In addition, our results hint an emphasis on preventive interventions on suicide attempts and depression, which are top causes of the attributable disease burden due to child maltreatment.

\section{Conclusion}

Our study demonstrated that lifetime disease and economic burden due to child maltreatment in Japan is substantial. Its disease burden was approximately equal to the burden of colon and rectum cancers or stomach cancer. In particular, it is important to include the longterm disease burden in future studies related to disease burden and cost of illness for both technical and policy perspectives.

\section{Supplementary information}

Supplementary information accompanies this paper at https://doi.org/10. 1186/s12889-020-09397-8.

Additional file 1 Table a1. Studies included in the quantitative synthesis. Table a2. Health outcomes and pooled ORs used in this study (AHT not included). Table a3. Incidence rate by age and average onset age, based on the number of consultation cases disposed about child abuse at child guidance centers.

Additional file 2 Systematics review (2018/5/10-2018/5/20)-find possible literature including Japanese studies on risk of health outcomes attributable to child maltreatment. Figure a1. Study selection (PRISMA) flow diagram.

\section{Abbreviations}

DALYs: Disability-Adjusted Life Years; PAFs: population attributable fractions; GDP: gross domestic product; MHLW: Ministry of Health, Labour and Welfare; WDV: witnessing domestic violence; $\mathrm{AHT}$ : abusive head trauma;

ICD: International Classification of Diseases; GBD: Global Burden of Disease; RR: risk ratio; OR: odds ratio; ACEs: adverse childhood experiences

\section{Acknowledgements}

We are grateful thank members of Health Informatics Department, Kyoto University of Public Health School for their kind support.

\section{Authors' contributions}

MX and GR designed the study. MX did the calculation and draft the manuscript. GR and TY (Takahashi) contributed to the revise. TY (Tachibana), TB and NT critically reviewed and provided important intellectual feedback on the revise. All authors have read and approved the manuscript.

\section{Funding}

This study is granted by Health Labour Sciences Research Grant, Japan Agency for Medical Research and Development, and as part of an IPSS 
project on the realization of "Japan's Plan for Dynamic Engagement of All Citizens". The funders did not have any role in the study design, data collection, and analysis, interpretation of data or in writing the manuscript.

\section{Availability of data and materials}

All the raw data is publicly accessible from respective official website as reference (National healthcare expenditures 2016 and Patient Survey 2014). The datasets analysed during the current study are available from the corresponding author on reasonable request.

\section{Ethics approval and consent to participate}

Not applicable.

\section{Consent for publication}

Not applicable.

\section{Competing interests}

The authors declare no conflict of interest.

\section{Author details}

'Department of Health Policy, National Center for Child Health and Development, Tokyo, Japan. ${ }^{2}$ Department of Health Informatics, Kyoto University School of Public Health, Kyoto, Japan. ${ }^{3}$ Department of Empirical Social Security Research, National Institute of Population and Social Security Research, Uchisaiwaicho 2-2-3, Chiyoda-ku, Tokyo 1000011, Japan. ${ }^{4}$ Maternal-Child Psychiatry, Department of Psychosocial Medicine, National Center for Child Health and Development, Tokyo, Japan. ${ }^{5}$ Faculty of Economics, Saitama University, Sakura-ku, Japan.

\section{Received: 14 March 2020 Accepted: 17 August 2020}

\section{Published online: 27 August 2020}

\section{References}

1. Gilbert R, Widom CS, Browne K, Fergusson D, Webb E, SJTI J. Burden and consequences of child maltreatment in high-income countries. Lancet. 2009;373(9657):68-81.

2. Number of consultation cases disposed about child abuse at child guidance centers in Japan 2016 (in Japanese) [https://www.e-stat.go.jp/stat-search/ files? page $=1 \&$ layout $=$ datalist $\&$ tstat $=000001034573 \&$ cycle $=8 \&$ tclass $1=$ $000001108815 \&$ tclass $2=000001108820 \&$ second $2=1]$.

3. Definition and Present Condition of Child Abuse (in Japanese) [https:// www.mhlw.go.jp/seisakunitsuite/bunya/kodomo/kodomo_kosodate/dv/ about.html]. Accessed 24 July 2018.

4. Currie J, Spatz Widom C. Long-term consequences of child abuse and neglect on adult economic well-being. Child maltreatment. 2010;15(2):11120.

5. Hughes K, Bellis MA, Hardcastle KA, Sethi D, Butchart A, Mikton C, Jones L, Dunne MP. The effect of multiple adverse childhood experiences on health: a systematic review and meta-analysis. Lancet Public Health. 2017;2(8):e35666.

6. FY 2017 budget outline for Child Abuse Prevention [https://www.mhlw.go. jp/file/05-Shingikai-11901000-Koyoukintoujidoukateikyoku-Soumuka/002_1. pdf]. Accessed 24 July 2018.

7. FY 2018 budget outline for Child Abuse Prevention [https://www.mhlw.go. jp/file/06-Seisakujouhou-11900000-Koyoukintoujidoukateikyoku/0000180499. pdf]. Accessed 24 July 2018.

8. FY 2015 budget outline for Child Abuse Prevention [https://www.mhlw.go jp/file/05-Shingikai-12601000-Seisakutoukatsukan-Sanjikanshitsu_ Shakaihoshoutantou/0000058633.pdf]. Accessed 24 July 2018.

9. The economics of child abuse, a study of San Francisco [https:// safeandsound.org/wp-content/uploads/2017/09/economicsofabuse_report_ sfcapc1.pdf]. Accessed 24 July 2018.

10. Fang X, Brown DS, Florence CS, Mercy JA. The economic burden of child maltreatment in the United States and implications for prevention. Child Abuse Negl. 2012;36(2):156-65.

11. Habetha S, Bleich S, Weidenhammer J, Fegert JM. A prevalence-based approach to societal costs occurring in consequence of child abuse and neglect. Child Adolesc Psychiatry Ment Health. 2012;6(1):35.

12. McCarthy MM, Taylor P, Norman RE, Pezzullo L, Tucci J, Goddard C. The lifetime economic and social costs of child maltreatment in Australia. Child Youth Serv Rev. 2016;71:217-26.
13. Wada I, Igarashi A. The social costs of child abuse in Japan. Child Youth Serv Rev. 2014:46:72-7.

14. Miller TR, Steinbeigle R, Wicks A, Lawrence BA, Barr M, Barr RGJP. Disabilityadjusted life-year burden of abusive head trauma at ages 0-4. Pediatrics. 2014;134(6):e1545-50.

15. Fang $X$, Fry DA, Brown DS, Mercy JA, Dunne MP, Butchart AR, Corso PS, Maynzyuk K, Dzhygyr Y, Chen Y, et al. The burden of child maltreatment in the East Asia and Pacific region. Child Abuse Negl. 2015;42:146-62.

16. Corso PS, Fertig AR. The economic impact of child maltreatment in the United States: are the estimates credible? Child Abuse Negl. 2010;34(5):296304.

17. Macroeconomics and Health: Investing in Health for Economic Development [http://whqlibdoc.who.int/publications/2001/924154550x.pdf]. Accessed 24 July 2018.

18. Segel JE. Cost-of-illness studies-a primer. RTI-UNC Center of Excellence in Health Promotion Economics. 2006;1:39.

19. Jo C. Cost-of-illness studies: concepts, scopes, and methods. Clin Mol Hepatol. 2014;20(4):327.

20. Metrics: Population Attributable Fraction (PAF) [http://www.who.int/ healthinfo/global_burden_disease/metrics_paf/en/]. Accessed 24 July 2018.

21. Norman RE, Byambaa M, De R, Butchart A, Scott J, Vos T. The long-term health consequences of child physical abuse, emotional abuse, and neglect: a systematic review and meta-analysis. PLoS Med. 2012;9(11):e1001349.

22. Kalmakis KA, Chandler GE. Health consequences of adverse childhood experiences: a systematic review. J Am Assoc Nurse Pract. 2015;27(8):457-65.

23. UNICEF. Child maltreatment, prevalence, incidence and consequences in the East Asia and Pacific region. New York: UNICEF; 2012.

24. Rothman KJ. Epidemiology: an introduction: Oxford university press; 2012.

25. Joyce T, Huecker MR. Pediatric Abusive Head Trauma (Shaken Baby Syndrome) [Updated 2020 Aug 15]. In: StatPearls [Internet]. Treasure Island (FL): StatPearls Publishing; 2020. Available from: https://www.ncbi.nlm.nih. gov/books/NBK499836/.

26. Yamaoka Y, Fujiwara T, Fujino Y, Matsuda S, Fushimi K. Incidence and age distribution of hospitalized presumptive and possible abusive head trauma of children under 12 months old in Japan. J Epidemiol. 2020;30(2):91-7. https://doi.org/10.2188/jea.JE20180094.

27. Japanese population projection 2016 [http://www.stat.go.jp/data/jinsui/2016 np/]. Accessed 24 July 2018.

28. Summary of Patient Survey 2014 [https://www.mhlw.go.jp/english/ database/db-hss/sps_2014.html]. Accessed 24 July 2018.

29. Kirigia JM, Mburugu GN, Huka GS. The indirect cost of disability adjusted life years lost among the elderly in Kenya. Int Arch Med. 2017;10(213). https:// doi.org/10.3823/2483.

30. Mortality and global health estimates [http://www.who.int/gho/mortality_ burden_disease/en/]. Accessed 24 July 2018.

31. Japan GDP - Gross Domestic Product [https://countryeconomy.com/gdp/ japan?year=2016]. Accessed 24 July 2018.

32. The results of verification of death cases caused by child abuse. (14 th report) [https://www.mhlw.go.jp/stf/seisakunitsuite/bunya/0000173329_ 00001.html]. Accessed 24 July 2018

33. Miller TR, Steinbeigle R, Wicks A, Lawrence BA, Barr M, Barr RG. Disabilityadjusted life-year burden of abusive head trauma at ages 0-4. Pediatrics. 2014;134(6):e1545-50. https://doi.org/10.1542/peds.2014-1385.

34. Shiroiwa T, Fukuda T, Ikeda S, Takura T, Moriwaki K. Development of an official guideline for the economic evaluation of drugs/medical devices in Japan. Value Health. 2017;20(3):372-8.

35. Moore SE, Scott JG, Ferrari AJ, Mills R, Dunne MP, Erskine HE, Devries KM, Degenhardt L, Vos T, Whiteford HA. Burden attributable to child maltreatment in Australia. Child Abuse Negl. 2015;48:208-20.

\section{Publisher's Note}

Springer Nature remains neutral with regard to jurisdictional claims in published maps and institutional affiliations. 